\title{
Children's estimates of food portion size: the effect of timing of dietary interview on the accuracy of children's portion size estimates
}

\author{
E. Foster ${ }^{1 *}$, M. O'Keeffe ${ }^{2}$, J. N. S. Matthews ${ }^{2}$, J. C. Mathers ${ }^{1}$, M. Nelson ${ }^{3}$, K. L. Barton ${ }^{4}$, W. L. Wrieden ${ }^{4}$ \\ and A. J. Adamson ${ }^{1}$ \\ ${ }^{1}$ Human Nutrition Research Centre, School of Clinical Medical Sciences, University of Newcastle, Room M1151, 1st Floor, William \\ Leech Building, Framlington Place, Newcastle upon Tyne, NE2 4HH, UK \\ ${ }^{2}$ School of Mathematics and Statistics, Newcastle University, Newcastle upon Tyne, UK \\ ${ }^{3}$ Department of Nutrition and Dietetics, Kings College London, London, UK \\ ${ }^{4}$ Centre for Public Health Nutrition Research, University of Dundee, Dundee, UK
}

(Received 10 August 2006 - Revised 25 April 2007 - Accepted 30 April 2007)

For food intakes to be converted into nutrient intakes a measure or estimate of the amount of food consumed is required. A number of methods have been developed to assist subjects in providing an estimate of portion size. Children's ability to use perception, conceptualisation and memory skills to estimate food portion size has not been investigated systematically. The aim of the present study was to test the effect of the timing of a dietary interview on the accuracy of estimates of food portion sizes made by children, using food photographs, food models and an interactive portion size assessment system, developed for use with children and based on portion sizes of foods consumed by children. Children ( $n$ 108) aged 4-14 years were supplied with known quantities of foods and asked to estimate the portion size of each food using each of the three portion size assessment tools. Interviews took place (a) with the food in view, (b) just after the child had eaten the food or (c) $24 \mathrm{~h}$ after the child had eaten the food. There were no significant differences in children's ability to estimate food portion size (either as served or as eaten) with timing of interview. That is, children were as accurate in their estimates of portion size $24 \mathrm{~h}$ after consuming the food as when the food was in view. Under these conditions many children were able to estimate food portion size utilising perception, conceptualisation and memory skills.

Portion size estimation: Children: Interview timing

Assessing nutrient intake at the individual level requires determination of portion size for each food consumed. Weighing all foods consumed places a large burden on the subject and often results in under-reporting of food intake ${ }^{1}$. Alternative methods to weighing have been developed including those that rely on subjects' estimates of portion size. Tools are available to assist the subject in this estimation such as food photographs, food replicas and food models ${ }^{2-4}$. However, the application of these tools in improving portion size estimation by children has not been investigated systematically ${ }^{5}$.

In addition to the problems encountered with adults completing dietary assessment studies such as motivational issues, subject recording bias and subject selection bias, when children are the subjects literacy, writing skills, limited food recognition skills, memory constraints and concentration span are further issues.

In subjects where memory is a concern the time delay between the subject consuming the food and reporting the consumption may be critical. However, there has been little investigation into the effect on the accuracy of estimates of the length of time between consuming a food and estimating portion size. Indeed there has been limited research into the effect of time delay on the accuracy of reporting of the type of foods consumed. Smith et al. ${ }^{6}$ investigated the ability of adults to recall food items consumed with increasing time intervals between consuming the food and reporting the consumption. The length of time between consuming and reporting the foods investigated were much longer than would usually be used in a dietary recall. Subjects were asked to record their total dietary intake for either 2 or 4 weeks. The subjects were then invited to return either at the end of the recording period or 2, 4 or 6 weeks after the end of the recording period and were asked to recall all items consumed during the recording period without the aid of the record. Not surprisingly the authors reported a decrease in the number of positive matches and an increase in the number of foods reported but not recorded with increased time interval. Armstrong et al. $^{7}$ asked adult subjects to keep a record of all food and drinks consumed during a $24 \mathrm{~h}$ period and to return after $1,2,4$ or $8 \mathrm{~d}$ to report orally the foods consumed during the recording period. The time intervals tested by Armstrong et ll $^{7}$ are more likely in dietary interviews than the periods of several weeks tested by Smith et al. ${ }^{6}$. Again there was a decrease in the accuracy of reporting with an increased time interval.

Abbreviations: FIF, food in front; IPSAS, interactive portion size assessment system; JAE, just after eating.

* Corresponding author: Dr Emma Foster, fax +44 191 2225581, email Emma.Foster@ncl.ac.uk 
Subjects correctly reported $92 \%$ of foods consumed $1 \mathrm{~d}$ after recording but this dropped with increasing time interval to $86 \%$ after $2 \mathrm{~d}, 81 \%$ after $4 \mathrm{~d}$ and $78 \%$ after $8 \mathrm{~d}$. Both omissions and intrusions (foods reported as consumed which did not appear on the record of intake) increased steadily as the time interval between consuming and recalling the food increased. Even $1 \mathrm{~d}$ after recording, $75 \%$ of subjects omitted at least one food from the recall and $23 \%$ of subjects reported foods which were not recorded on the record of intake. This level of error for adults reporting intake soon after consumption suggests a short time interval would be essential to obtain accurate reports of intake from children. Note, however, that this is not true validation since it relies on subjects' initial records of the foods consumed and it is possible that some of the intrusions were valid reports of foods which were consumed but which the subject omitted to report in the original record of intake. Furthermore, the accuracy of reports in a 'real-life' recall of intake is likely to be lower as the act of recording the intake may enhance the subsequent recall of the foods consumed.

If food items can be forgotten in such a short period of time, it is likely that retention of information on the portion sizes consumed will be even poorer. A study which validated 9-10-year-old children's estimates of food portion size against observer assessment found estimates made during a $24 \mathrm{~h}$ recall were more accurate than estimates made during a FFQ, covering the past $5 \mathrm{~d}$, or dietary record interview, covering the previous $3 \mathrm{~d}^{8}$. The authors suggest this difference was due to the short time interval between consuming and reporting the food. Frobisher \& Maxwell ${ }^{9}$ examined the ability of adults and children to estimate the portion sizes of foods which they had served themselves either just after having seen the food, or 3 to $4 \mathrm{~d}$ after having seen the food. For this study the food was not consumed. They did not find any important differences in ability to estimate portion size using food photographs ${ }^{4}$ whether estimates were made just after having seen the food or 3 to $4 \mathrm{~d}$ later. As subjects estimated the amount of food just after seeing it and were then recalled 3 to $4 \mathrm{~d}$ later to provide a portion size estimate for that same food the authors noted that the subject may have just been recalling their previous response rather than conceptualising the actual portion of food ${ }^{9}$.

The use of portion size assessment tools when used during a $24 \mathrm{~h}$ recall interview or food diary interview relies on three cognitive processes: perception, conceptualisation and memory. Perception (as related to portion size assessment) can be defined as the ability to relate an amount of food that is present in reality to an amount depicted in a portion size assessment tool. Conceptualisation is a subject's ability to make a mental construct of an amount of food which is not present in reality.

\section{Method}

The aim of the present study was to assess the effect of timing on perception, conceptualisation and memory on the ability of children to estimate food portion size using three portion size assessment tools.

Ethical approval for the study was granted by the Newcastle and North Tyneside Health Authority. Two primary schools and one secondary school were recruited to take part in the study. A recruitment letter detailing what the study involved was sent to the parents of all children attending each school and parental consent was sought for participation in the study.

Three portion size assessment tools were developed. These were food photographs, food models and an interactive portion size assessment software (IPSAS) package. All three tools were developed for use with children and based on portion sizes consumed by children. Full details of tool development are given elsewhere ${ }^{10}$. Children were asked to quantify foods using each of the portion size assessment tools.

The effect of perception, conceptualistion and memory on children's ability to estimate portion sizes using the three tools was assessed using three interview types:

(1) 'Food in front' (FIF) interview. Children's perception of food portion size was tested by the FIF interview. For this interview plates of food of known weights were prepared and the children were asked to estimate the amount of food in front of them using one of the three portion size assessment tools.

(2) 'Just after eating' (JAE) interview. Children's perception and conceptualisation of food portion size was tested by the JAE interview. For this interview children were asked to eat foods of known weights and any leftovers were weighed. Within $30 \mathrm{~min}$ of consuming the food the children were asked to estimate the amount of food that they had been served and the amount they had left.

(3) ' $24 \mathrm{~h}$ Recall' interview. Children's perception, conceptualisation and memory of food portion size were tested by the $24 \mathrm{~h}$ recall interview. For this interview children were asked to eat foods of known weights and any leftovers were weighed. The following day the children were interviewed and asked to estimate the amount of food that they had been served and the amount they had left.

Children aged 4-16 years were included in the study, subdivided into four age groups; 4-6 years, 7-10 years, 11-14 years and $15-16$ years.

In order for all children in the study to complete all interview types with each of the three tools each child would need to have been fed six times and interviewed nine times. This was not deemed as likely to be acceptable for either the children or the participating school. A randomised incomplete block design was used so that each child completed only five interviews but all combinations of interview type and tool were equally represented over the whole study and administered in a randomised order.

The foods selected to be included in the study were foods commonly consumed by children. The foods were selected using information available on the food choices of children. The principal data source was the National Diet and Nutrition Survey: young people aged 4 to 18 years ${ }^{11}$. Foods of a variety of appearances, consistencies and textures were selected for inclusion in the study. They were foods commonly consumed by all of the age groups included in the study, excluding those which are generally presented in predefined amounts (such as individual portion packs). They included beverages and liquid foods (milk and orange squash), uniform solid foods of undefined portion size (cheese), mixed-texture foods (baked beans), foods served in distinct pieces (chips) and single-item foods (fruit). 
Twelve foods were selected for testing to be provided to the children as three meals:

Breakfast: cornflakes, milk and sugar;

Lunch: sausage, baked beans, chips, ketchup and orange squash;

Snack: apple and cheese sandwich (bread, margarine and cheese, as slices).

The portion sizes presented in the tools were based on the weights of foods consumed by children in the National Diet and Nutrition survey which were calculated as described by Barton et $a{ }^{12}{ }^{12}$. Four versions of each tool were developed depicting portion sizes appropriate to children aged 4-6, $7-10,11-14$ and $15-16$ years. Each tool presented portion sizes for estimation of the amount of food served and left over (for further details, see Foster et $a{ }^{10}{ }^{10}$ ). The children were served a mixture of small, medium and large portions based on the 25th, 50th and 75th centile, respectively, of weight of food served according to data from the National Diet and Nutrition survey ${ }^{11}$.

The data were analysed in two ways:

(1) The child's estimate of the amount of food served was compared with the actual weight of food served with no account of leftovers.

(2) The child's estimate of the amount of food they ate (child's estimate of the weight of food served - child's estimate of leftovers) was compared with the actual weight of food consumed by the child.

A multilevel model was used, fitted in MLWin (Institute of Education, University of London, London) ${ }^{13}$. The child was fitted as a random effect and the effects of the tools and test types were assessed using fixed effects.

The outcome variable was successively, (1) the ratio of the amount of food estimated by the child to have been served to the amount actually served, and (2) the ratio of the amount estimated to have been eaten to the amount actually eaten. The former was computed for twelve foods and the latter for eight since it proved impractical to measure the amounts left for the remaining four foods which were those served as a snack. The distribution of ratios is generally skewed and the analysis was therefore performed on the logarithms of the ratios (base 10) and the results presented in terms of ratios of geometric means.

The accuracy and precision of the children's estimates of portion size were assessed by plotting the geometric mean of the ratio of the child's estimate of the amount of food served (or consumed) against the actual weight of the food served (or consumed). The error bars depict the mean plus and -2 standard deviations and give a measure of the precision of the estimates. Accuracy is defined as the proximity of the mean of the children's estimates of portion size to the actual weight of the food served. Precision is defined as the variability of individual estimates around the mean.

The purpose of this analysis was to assess the effect of time of interview on the accuracy of estimates. For this reason the data are presented by interview type and by age groups for all foods included in the study. Data for differences by type of assessment tool (food models, food photographs and IPSAS) are not included in the present analysis and have been reported elsewhere $^{10}$.

\section{Results}

A total of 108 children aged 4-14 years participated in the study. The aim was to recruit thirty-six children in each of the four age groups (4-6 years, 7-10 years, 11-14 years and 15-16 years). This was achieved comfortably in all but the oldest group (Table 1). Four children who were recruited at age 6 years became age 7 years before completing the study. The 15-16-year-old children proved difficult to recruit; despite increasing the incentive offered to children taking part (from a $£ 10$ voucher to $£ 15$ ) and recruiting a further school to take part, the target number of children was not achieved. No results are presented for estimates by children aged 15-16 years.

Tables 2 and 3 show the accuracy of children's estimates of portion size for FIF, JAE and $24 \mathrm{~h}$ recall interviews using all three tools. The ratio is the geometric mean of the ratio of the child's estimate of the portion size of the food to the actual portion size, therefore the closer the value is to 1 the more accurate the estimates. There was a large variation in the accuracy of estimates between types of food. Apples were the most accurately estimated food, the portion size of baked beans and tomato ketchup tended to be underestimated and the portion size of sugar, margarine and cheese all tended to be overestimated.

Table 2 shows the differences in portion size estimation ('as served') by interview type and age. Although for individual foods some $P$ values are less than 0.05 , the broad picture is that there is little evidence that interview type affects the reported ratio. That is, there is no evidence that children's ability to estimate portion size is significantly different $24 \mathrm{~h}$ after eating from just after eating a food or indeed when the food is in view. Of the thirty-six observations, the FIF interview gave the most accurate mean estimate of portion size nine times, the JAE interview nine times and the $24 \mathrm{~h}$ interview fourteen times. On four occasions two or more interview types resulted in mean estimates which were of equal accuracy. However, these

Table 1. Subject recruitment and interview completion

\begin{tabular}{|c|c|c|c|c|c|c|c|c|}
\hline \multirow[b]{2}{*}{ Age group (years) } & \multirow[b]{2}{*}{ Recruitment target $(n)$} & \multirow[b]{2}{*}{ Approached $(n)$} & \multicolumn{2}{|c|}{ Consenting } & \multirow[b]{2}{*}{ Included $(n)$} & \multirow[b]{2}{*}{ Interviews intended $(n)$} & \multicolumn{2}{|c|}{ Interviews completed } \\
\hline & & & $n$ & $\%$ & & & $n$ & $\%$ \\
\hline $4-6$ & 36 & 326 & 147 & 45 & 32 & 160 & 148 & 93 \\
\hline $7-10$ & 36 & 548 & 244 & 45 & 40 & 200 & 179 & 90 \\
\hline $11-14$ & 36 & 990 & 125 & 13 & 36 & 180 & 132 & 73 \\
\hline Total & 144 & 2533 & 572 & 23 & 108 & 540 & 459 & 85 \\
\hline
\end{tabular}


Table 2. Differences in portion size estimation by interview type and age (as served) (Mean ratios)

\begin{tabular}{|c|c|c|c|c|c|}
\hline \multirow[b]{2}{*}{ Food } & \multirow[b]{2}{*}{ Age group (years) } & \multicolumn{3}{|c|}{ Mean ratio* } & \multirow[b]{2}{*}{$P$} \\
\hline & & FIF & JAE & $24 \mathrm{~h}$ recall & \\
\hline \multirow[t]{3}{*}{ Apple } & $4-6$ & 1.00 & 1.00 & 0.97 & 0.68 \\
\hline & $7-10$ & 0.94 & 0.97 & 1.00 & 0.56 \\
\hline & $11-14$ & 0.88 & 0.87 & 0.89 & 1.00 \\
\hline \multirow[t]{3}{*}{ Baked beans } & $4-6$ & 0.63 & 0.74 & 0.62 & 0.36 \\
\hline & $7-10$ & 0.73 & 0.77 & 0.73 & 0.65 \\
\hline & $11-14$ & 0.60 & 0.73 & 0.81 & 0.01 \\
\hline \multirow[t]{3}{*}{ Bread } & $4-6$ & 0.90 & 0.85 & 0.92 & 1.00 \\
\hline & $7-10$ & 0.98 & $1 \cdot 10$ & 0.99 & 0.68 \\
\hline & $11-14$ & 0.86 & 0.97 & 0.97 & 0.24 \\
\hline \multirow[t]{3}{*}{ Cheese } & $4-6$ & 1.70 & 1.42 & 1.83 & 0.51 \\
\hline & $7-10$ & 1.40 & 1.92 & 1.64 & 0.09 \\
\hline & $11-14$ & 1.37 & 1.32 & 1.62 & 0.25 \\
\hline \multirow[t]{3}{*}{ Chips } & $4-6$ & 0.88 & 1.08 & 0.92 & 0.12 \\
\hline & $7-10$ & 0.92 & 0.98 & 1.06 & 0.12 \\
\hline & $11-14$ & 0.62 & 0.77 & 0.73 & 0.07 \\
\hline \multirow[t]{3}{*}{ Cornflakes } & $4-6$ & 1.54 & 1.55 & 1.50 & 0.84 \\
\hline & $7-10$ & 1.38 & 1.29 & $1 \cdot 19$ & 0.24 \\
\hline & $11-14$ & 1.24 & $1 \cdot 12$ & $1 \cdot 19$ & 0.14 \\
\hline \multirow[t]{3}{*}{ Margarine } & $4-6$ & 1.63 & 1.94 & 1.62 & 0.55 \\
\hline & $7-10$ & 1.57 & 1.64 & 1.61 & 0.85 \\
\hline & $11-14$ & 1.52 & 1.47 & 1.45 & 0.94 \\
\hline \multirow[t]{3}{*}{ Milk } & $4-6$ & 1.21 & 1.23 & $1 \cdot 14$ & 0.81 \\
\hline & $7-10$ & 0.99 & 0.89 & 1.01 & 0.50 \\
\hline & $11-14$ & 0.96 & 1.00 & $1 \cdot 17$ & 0.15 \\
\hline \multirow[t]{3}{*}{ Sausages } & $4-6$ & $1 \cdot 21$ & $1 \cdot 16$ & $1 \cdot 14$ & 0.90 \\
\hline & $7-10$ & 1.01 & 1.07 & $1 \cdot 11$ & 0.50 \\
\hline & $11-14$ & 0.97 & 1.07 & $1 \cdot 11$ & 0.08 \\
\hline \multirow[t]{3}{*}{ Squash } & $4-6$ & 1.25 & $2 \cdot 15$ & 2.04 & $<0.001$ \\
\hline & $7-10$ & 1.27 & 1.79 & 1.96 & $<0.001$ \\
\hline & $11-14$ & $1 \cdot 19$ & $1 \cdot 30$ & 1.27 & 0.23 \\
\hline \multirow[t]{3}{*}{ Sugar } & $4-6$ & 1.73 & 3.00 & 2.49 & $<0.001$ \\
\hline & $7-10$ & 1.54 & $1 \cdot 30$ & 1.25 & 0.04 \\
\hline & $11-14$ & 1.20 & $1 \cdot 15$ & $1 \cdot 13$ & 0.62 \\
\hline \multirow[t]{3}{*}{ Tomato ketchup ketchup } & $4-6$ & 0.77 & 0.73 & 0.85 & 0.53 \\
\hline & $7-10$ & 0.76 & 0.65 & 0.56 & $<0.001$ \\
\hline & $11-14$ & 0.66 & 0.68 & 0.56 & 0.02 \\
\hline
\end{tabular}

${ }^{*}$ Ratio of the amount of food estimated by the child to have been served to the amount actually served.

differences were significant on six occasions where the FIF interview was most accurate and two occasions where the JAE interview and two where the $24 \mathrm{~h}$ interview were the most accurate.

Table 3 shows the results for the seven foods where it was practical to assess leftovers. As with the analysis on the portion sizes of foods served there is no clear evidence of differences between the interview types. The JAE interview gave the most accurate mean estimate of portion size ten times and the $24 \mathrm{~h}$ interview ten times. On one occasion the two interview types resulted in mean estimates that were of equal accuracy. The JAE interview was significantly more accurate than the $24 \mathrm{~h}$ recall interview on three occasions. Figs 1 and 2 show that the precision of estimates increases with age as evidenced by the narrowing of the error bars as age increases due to a reduced variability of estimates around the mean. Accuracy also increases with age as the mean ratio of estimated to actual weight of the food moves closer to 1 as age increases (Figs 1 and 2). There is no clear pattern for either accuracy or precision related to the timing of the interview.
The accuracy of the different tools is described elsewhere ${ }^{10}$. In brief, significant differences were found between the accuracy of estimates using the three tools. Children of all ages performed well using the IPSAS and food photographs. The accuracy and precision of estimates made using the food models were poor. Estimates of the amount of food served were more accurate than estimates of the amount consumed.

\section{Discussion}

Dietary surveys often include an interview at some time after the end of the recording period to clarify what foods were consumed, attempt to uncover any omissions and to assess the portion size of foods consumed. The present study set out to examine the accuracy of children's estimates of portion size when foods were in front of them, compared with JAE the food or $24 \mathrm{~h}$ after eating the food. There was no significant difference in children's ability to estimate food portion size (either as served or as eaten) with interview type. That is children were as accurate in their estimates of 
Table 3. Differences in portion size estimation by interview type and age (as eaten)

(Mean ratios)

\begin{tabular}{|c|c|c|c|c|}
\hline \multirow[b]{2}{*}{ Food } & \multirow[b]{2}{*}{ Age group (years) } & \multicolumn{2}{|c|}{ Mean ratio* } & \multirow[b]{2}{*}{$P$} \\
\hline & & JAE & $24 \mathrm{~h}$ recall & \\
\hline \multirow[t]{3}{*}{ Baked beans } & $4-6$ & 0.81 & 1.02 & 0.43 \\
\hline & $7-10$ & 0.74 & 0.83 & 0.45 \\
\hline & $11-14$ & 0.67 & 0.76 & 0.31 \\
\hline \multirow[t]{3}{*}{ Chips } & $4-6$ & 1.42 & $1 \cdot 21$ & 0.39 \\
\hline & $7-10$ & 1.02 & $1 \cdot 27$ & 0.03 \\
\hline & $11-14$ & 0.73 & 0.73 & 1.00 \\
\hline \multirow[t]{3}{*}{ Cornflakes } & $4-6$ & 1.98 & 1.76 & 0.74 \\
\hline & $7-10$ & 1.55 & $1 \cdot 24$ & 0.17 \\
\hline & $11-14$ & 1.31 & $1 \cdot 23$ & 0.31 \\
\hline \multirow[t]{3}{*}{ Milk } & $4-6$ & 1.57 & 1.44 & 0.63 \\
\hline & $7-10$ & $1 \cdot 16$ & 1.03 & 1.00 \\
\hline & $11-14$ & 1.36 & 1.57 & 0.53 \\
\hline \multirow[t]{3}{*}{ Sausages } & $4-6$ & 1.43 & 1.75 & 0.10 \\
\hline & $7-10$ & 1.08 & $1 \cdot 15$ & 0.43 \\
\hline & $11-14$ & 1.09 & $1 \cdot 17$ & 0.73 \\
\hline \multirow[t]{3}{*}{ Squash } & $4-6$ & 2.63 & $2 \cdot 36$ & 0.50 \\
\hline & $7-10$ & 1.81 & 1.98 & 0.43 \\
\hline & $11-14$ & 1.22 & $1 \cdot 30$ & 0.55 \\
\hline \multirow[t]{3}{*}{ Tomato ketchup } & $4-6$ & 0.86 & $1 \cdot 19$ & 0.02 \\
\hline & $7-10$ & 0.62 & 0.60 & 0.81 \\
\hline & $11-14$ & 0.67 & 0.50 & 0.02 \\
\hline
\end{tabular}

AE, just after eating.

${ }^{*}$ Ratio of the amount estimated to have been eaten to the amount actually eaten.

portion size $24 \mathrm{~h}$ after consuming the food as when the food was in front of them. Frobisher \& Maxwell ${ }^{9}$ also found no significant difference between adults' and children's estimates of portion size whether the estimate was made just after having seen the food or 3-4d later. However, in
Frobisher \& Maxwell's study ${ }^{9}$, as both estimates were made for the same portion of food the subjects may have relied on their memory of their previous estimate rather than their memory and re-conceptualisation of the size of the portion.

For the present study the children were required to attend a number of interviews on separate days to provide estimates of food portion sizes. They were therefore aware, after the first test, that they would be questioned about the portion sizes of the foods they were shown or that they consumed. This and the novel way in which the food was presented (participants were either asked to look at plates of foods or provided with foods to consume in a separate room away from their normal dining hall) is likely to have increased the attention paid by the children to the food and therefore improved memory. Covert observation and weighing of foods consumed by children in their normal environment is challenging but could give a better indication of the likely error with increasing time delay of portion size estimation of 'normal' diet.

The present study has established that, at least at a group level, children are able to estimate food portion size utilising perception, conceptualisation and memory skills although ability varied both across and within each age group. There was no evidence of any difference in mean estimates using $24 \mathrm{~h}$ recall when compared with FIF or JAE interviews. An interval of $24 \mathrm{~h}$ appears to be a short enough interval between eating and estimating the portion size of a food.

Further tests investigating time intervals of 1,2,3 and up to $7 \mathrm{~d}$ after consumption with both adults and children, to provide information on how long after eating the information on portion sizes for that particular eating event are retained, are required.

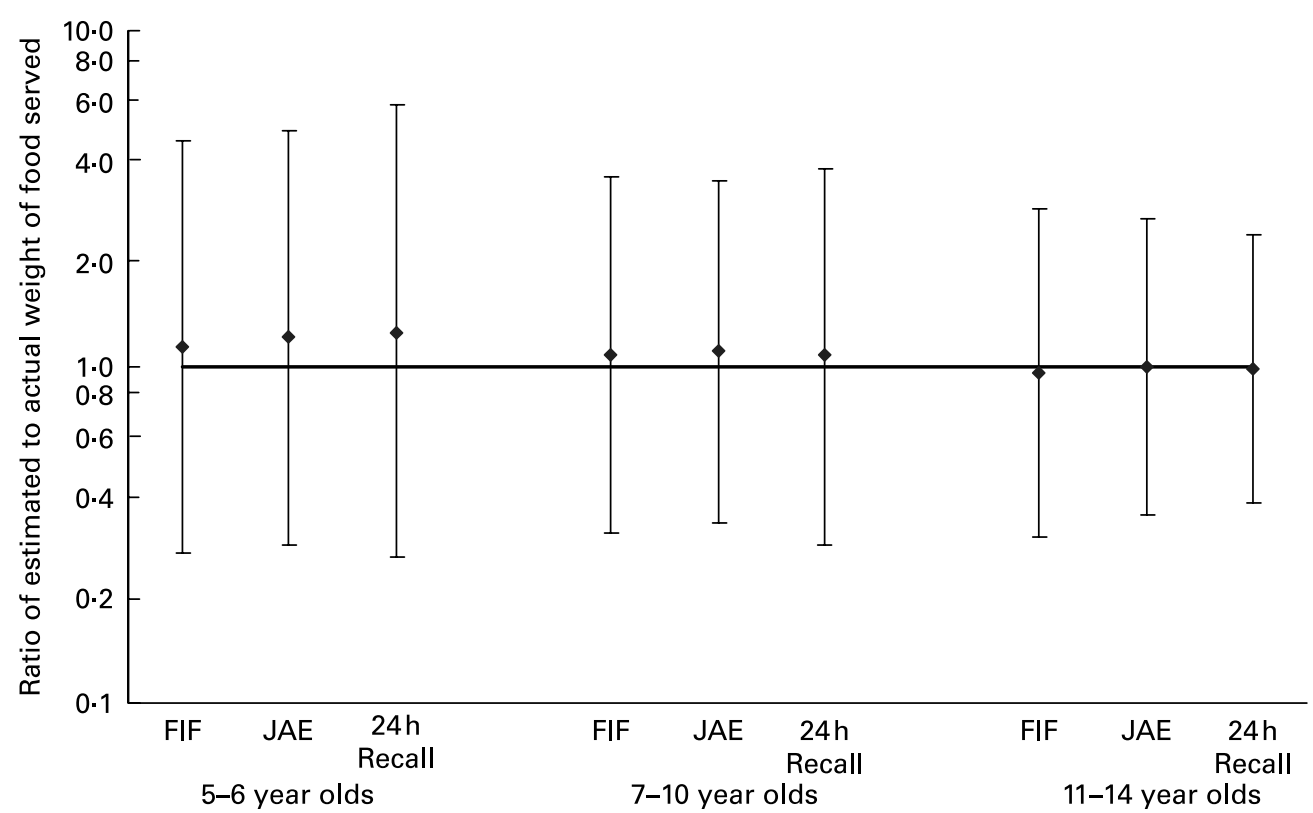

Fig. 1. Accuracy of children's estimates of food portion size by interview type and age (as served). FIF, food in front; JAE, just after eating. The line at 1.0 indicates where all the points would lie if estimates of portion size were completely accurate; ratios less than 1 indicate underestimation and those more than 1 indicate overestimation. Values are geometric means, with vertical bars representing \pm 2 standard deviations. 


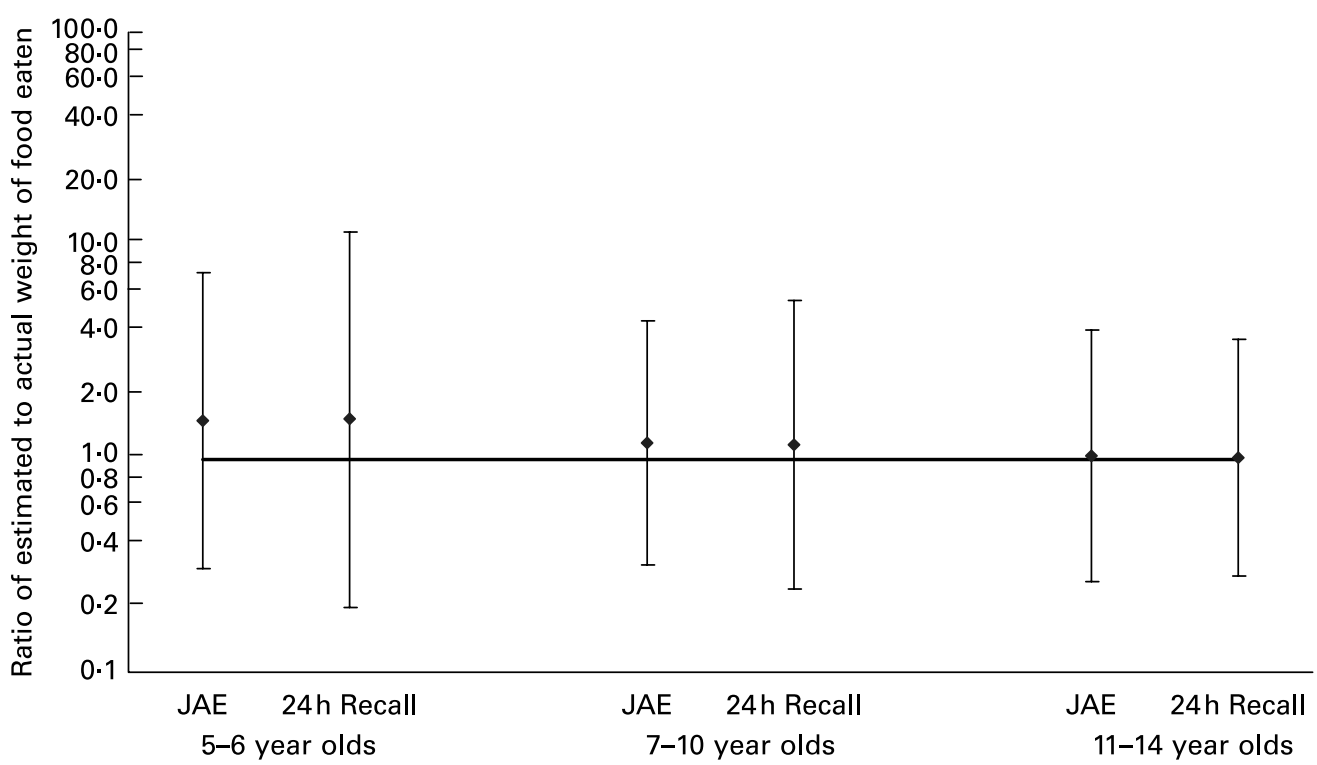

Fig. 2. Accuracy of children's estimates of food portion size by interview type and age (as eaten). JAE, just after eating. The line at $1 \cdot 0$ indicates where all the points would lie if estimates of portion size were completely accurate; ratios less than 1 indicate underestimation and those more than 1 indicate overestimation. Values are geometric means, with vertical bars representing \pm 2 standard deviations.

\section{Acknowledgements}

The authors gratefully acknowledge that the present research was commissioned by the Food Standards Agency (project number N08019). Special thanks to the Newcastle upon Tyne schools, teachers, parents and children who participated in the study.

\section{References}

1. Macdiarmid JI \& Blundell JE (1997) Dietary underreporting: what people say about recording their food intake. Eur J Clin Nutr 51, 199-200.

2. Hackett AF, Rugg-Gunn AJ, Appleton DR, Allinson M \& Eastoe JE (1984) Sugars-eating habits of 405 11- to 14-year-old English children. Br J Nutr 51, 347-356.

3. Cameron ME \& Van Staveren WA (1988) Manual on Methodology for Food Consumption Studies. Oxford: Oxford University Press.

4. Nelson M, Atkinson M \& Meyer J (1997) A Photographic Atlas of Food Portion Sizes. London: Ministry of Agriculture, Fisheries and Farming (MAFF) Publications.

5. Livingstone MBE \& Robson PJ (2000) Measurement of dietary intake in children. Proc Nutr Soc 59, 279-293.

6. Smith AF, Jobe JB \& Mingay DJ (1991) Retrieval from memory of dietary information. Appl Cognit Psychol 5, 269-296.
7. Armstrong AM, MacDonald A, Booth IW, Platts RG, Knibb RC \& Booth DA (2000) Errors in memory for dietary intake and their reduction. Appl Cogn Psychol 14, 183-191.

8. Crawford PB, Obarzanek E, Morrison J \& Sabry ZI (1994) Comparative advantage of 3-day food records over 24-hour recall and 5-day food frequency validated by observation of 9- and 10-year-old girls. J Am Diet Assoc 94, 626-630.

9. Frobisher C \& Maxwell SM (2003) The estimation of food portion sizes: a comparison between using descriptions of portion sizes and a photographic food atlas by children and adults. J Hum Nutr Diet 16, 181-188.

10. Foster E, Matthews JNS, Lloyd J, et al. (2007) Children's estimates of food portion size: the development and evaluation of three portion size assessment tools for use with children. Br J Nutr 99, 175-184.

11. Gregory J \& Lowe S (2000) National Diet and Nutrition Survey: Young People Aged 4 to 18 Years. London: H.M. Stationery Office.

12. Barton KL, Wrieden WL, Longbottom PJ, Adamson AJ \& Ogston SA (2003) How accurate are standard children's food portion sizes for estimation of dietary intakes of children of different ages? Proc Nutr Soc 62, 85A.

13. Goldstein H, Rasbash J, Plewis I, Draper D, Browne W, Yang M, Woodhouse G \& Healy M (1998) A User's Guide to MLwiN, Version 1.0. London: Institute of Education, University of London. 